\title{
Ortega, Spengler y el problema de la técnica
}

\section{Ortega, Spengler and the problem of technology}

\author{
JOSÉ MARÍA ATENCIA PÁEZ \\ Universidad de Málaga
}

Recibido: 30/12/14 Aceptado: 29/01/15

\begin{abstract}
RESUMEN:
El presente trabajo intenta un acercamiento al enfoque sobre la técnica de dos grandes críticos de la cultura contemporánea. Spengler y Ortega lo fueron y sus meditaciones sobre el significado de la técnica no se detienen en la consideración sobre su importancia económica o su relevancia social sino que se adentran en el sentido y significación antropológica. Por nuestra parte tratamos de poner de manifiesto sus coincidencias, así como sus discrepancias: contemplando la técnica como una función esencial de la vida. Frente a la desconsolada concepción de Spengler, Ortega ofrece una visión "deportiva" de la existencia del hombre más optimista.$$
\text { PALABRAS CLAVE: }
$$

TÉCNICA, VIDA, HOMBRE, CULTURA, ORTEGA, SPENGLER
\end{abstract}

\section{ABSTRACT:}

This article analyzes the view of technology offered by two of the main critics of the contemporary culture: Spengler and Ortega. Their meditations on the meaning of technology are focused not only on its economic or social relevance, but also on its anthropological meaning. I expose their coincidences and their discrepancies when they see technology as a essential function of life. In contrast with Spengler's disconsolate view, Ortega offers a more optimistic "sportive" conception of human being.

KEYWORDS:

TECHNOLOGY, LIFE, HUMAN BEING, CULTURE, ORTEGA, SPENGLER

(C) Contrastes. Revista Internacional de Filosofia, vol. XXI-Nº1 (2016), pp. 7-32. ISSN: 1136-4076

Departamento de Filosofía, Universidad de Málaga, Facultad de Filosofía y Letras Campus de Teatinos, E-29071 Málaga (España) 


\section{INTRODUCCIÓN}

Como ocurRe En otros Casos, la obra de Ortega es el destino de múltiples afluentes y el eco de influencias varias cuya rememoración suele arrojar luz sobre el sentido último de la no siempre patente intención orteguiana. Las páginas que siguen intentan un repaso de las concomitancias y diferencias entre las obras de Ortega y Spengler, dos de los críticos más lúcidos y penetrantes de la crisis de la modernidad occidental. En ambos casos se afronta el hecho de la técnica desde una óptica que trasciende su relevancia sociológica, económica e incluso histórica, para ahondar en su índole metafísica y su significación antropológica. Es en ese aspecto en el que queremos centrar nuestra reflexión.

Oswald Spengler publicó El hombre y la técnica en 1931. Ortega tuvo conocimiento de sus tesis principales desde la publicación de La decadencia de Occidente, ${ }^{1}$ cuyo prólogo a la edición española redactó con poco entusiasmo. En cualquier caso, las referencias al autor alemán no son infrecuentes en su obra, lo que no es de extrañar si se tiene en cuenta la serie de similitudes, ciertamente visibles, entre las tesis fundamentales de ambos autores.

\section{SPENGLER: LA DECADENCIA DE OCCIDENTE}

Oswald Spengler (1880-1936) ha sido el más conocido de los seguidores de Nietzsche y su obra La decadencia de Occidente partió, para abandonarlo, de un contexto dominado por el positivismo progresista imperante en el siglo XIX, evolucionando en el sentido de una ciclografía vitalista. En efecto, si en su época la opinión pública permanecía afincada en la creencia en el progreso, también empezaba a manifestarse el interés por la revisión en profundidad de la imagen del mundo histórico. Este movimiento se contraponía a la visión de la historia como simple e indiferente registro de hechos. Surgía una exigencia de síntesis y de visión filosófica.

Dicha obra ejerció una influencia enorme en una época que parecía encontrarse a la espera de un libro así, quizá como consecuencia del pesimismo tras la guerra y de la popularidad y carácter «evidente» de la asimilación de la historia de la humanidad a la evolución personal de los seres humanos, además de por su portentosa erudición germánica». Spengler fue un escritor grandilocuente, autoritario, una especie de dictador en posesión de un gigantesco material histórico que le permitió desarrollar con audacia un nuevo sistema de la historia universal.

El propósito consistía nada menos que en predeterminar la historia y seguir el destino de la cultura europea occidental «en los estadios aún no transcurridos» $(1,3)$. El subtítulo del primer volumen, Bosquejo de una morfología de

1 El primer tomo de su trabajo apareció ya en el verano de 1918; el segundo, en 1923. 
la historia universal, apunta a la teoría de las formas. La aparición de la obra supuso un éxito sin precedentes, ${ }^{2}$ si bien estuvo rodeada de polémica y su propio autor pareció condenado a la controversia y al malentendido, tanto como a la celebridad. El público saludó entusiasmado un libro que parecía iluminar aquel momento de la vida alemana; en cambio, las críticas y reproches por parte del mundo académico abundaron en la necesidad de mayores dosis de justificación filosófica, pero también en las acusaciones de ser el autor un simple amateur y en el reproche de una carencia de fundamento científico que él mismo no ocultaría; más tarde, el nacionalsocialismo trataría de atraerlo a sus filas, sin éxito, aunque la figura de Spengler nunca se ha librado totalmente de su supuesta proximidad al hitlerismo. Por lo demás, la Segunda Guerra mundial lo convirtió retrospectivamente en el malhadado profeta de enormes calamidades.

O sea, fue visto como un libro escrito por un periodista que practica el intrusismo en el ámbito de la historia, defendiendo el determinismo (determinismo que no ha sido mal recibido en el caso del materialismo histórico y «científico»), libro eurocéntrico, para el cual «Historia universal» equivale a «Historia occidental», siendo las demás historias objeto de apresurada visita en busca de alguna homología superficial, anécdotas arrancadas del conjunto o de corroboraciones laterales consideradas relevantes o significativas únicamente desde la arbitrariedad.

Por si fuera poco, el libro parece defender una óptica nacionalista «teutona», en una línea que no iba a tardar en dar sus frutos en el seno del movimiento nazi $^{3}$. Su acento vitalista, visible por ejemplo en la idea de «eterno retorno» de lo mismo en la sucesión de las diferentes culturas, la distinción entre moral de señores y moral de esclavos, entre la vida creadora y la vida decadente y la afirmación de esa vida como fundamento previo de toda cultura. Son particularmente patentes, por un lado, la influencia del Darwinismo, que concebía la vida como lucha y competencia (Occidente, en su opinión, está condenado a una lucha sin piedad por el dominio del mundo) y de la crítica nietzscheana de la cultura, contemplada desde las claves de «decadencia» y «voluntad de poder».

Para Spengler la ciencia positiva se hace una concepción insuficiente de la temporalidad, y, por tanto, de la historia, a la que espacializa y cosifica,

2 Como autor tuvo un éxito único: 53.000 ejemplares se vendieron entre 1918 y 1922, del primer tomo de la obra La decadencia de Occidente, que en sus 615 páginas contiene lo esencial de la nueva interpretación de la historia y que fue objeto de innumerables discusiones. En 1911 comenzó a escribir sus pensamientos, dándoles, a propósito de la obra de Otto Seeck Historia de la decadencia del mundo antiguo, el título que más tarde iba a producir tanta sensación.

3 No rechazaríamos esta crítica; pero tampoco conviene olvidar que Spengler se opuso al hitlerismo, y no militó en el NSDAP como sí hiciera Heigegger; dicho lo cual, es cierto que su influencia en el nazismo se dio un en plano más hondo, decisivo, sutil y global que el de otros pensadores. 
con objeto de manejar y dominar la materia y el espacio. Lo que se halla en el origen de esta tendencia dominadora no es sino la «angustia cósmica», verdadero origen de la ciencia. Pero a la ciencia se le escapa la vida y con ella la temporalidad. Con mucho más motivo, se le escapa la vida humana, ya que si la no humana (animal, vegetal) es mera existencia, la humana es vida consciente de sí misma y por tanto, temporalidad.

La angustia cósmica se expresa en la nostalgia y el miedo. Son estos impulsos básicos los que permiten comprender la peculiaridad de las grandes culturas. La nostalgia cósmica (el deseo de la psique de ascensión y plenitud) y el miedo cósmico (el sentimiento de consunción, de soledad en el universo) pugnan por manifestarse de modo diverso en todas las culturas. Las creaciones de una cultura son en su núcleo interior configuraciones del miedo cósmico, ya se trate de la magia verbal de los primitivos o de la terminología científica de una gran civilización, dentro de la cual los conceptos de evolución, existencia, energía y átomo tienen la misma función que las palabras mágicas.

La idea fundamental de la obra, prefigurada en el propio método fisiomático utilizado para afrontar las culturas observándolas sin prejuicios cientifistas, es lo que le hacía creerse a Spengler en condiciones de descifrar el enigma de la Historia e incluso prever su curso. De esta vida consciente y temporal, surge la vida espiritual, con todas sus posibilidades, que buscan realizarse en la forma de un «estilo» concreto, de una cultura. Las culturas surgen, pues, de la vitalidad y viven en el seno de un conjunto de vivencias que les son propias. Para Spengler las culturas son seres vivos y, como todos los demás, nacen y crecen sin meta, sin finalidad ni justificación: sin otro propósito que afirmarse, a partir de una «protovivencia» del mundo, geográficamente condicionada.

Por ejemplo, es el paisaje natural el responsable primero de la existencia de una «claridad griega» que alcanzará su expresión en Euclides y, como este paisaje es insustituible, una cultura no puede ser intercambiada, sustituida, o influida por ninguna otra. A cada una pertenece una morfología o mutación formal de cada estilo de vida que la configura, en una metamorfosis comparable a las estaciones del año y a las edades de la vida humana. Por otro lado, las culturas no pueden sustraerse a una necesidad íntima, a su destino, de modo que el futuro puede predecirse.

La obra entra en conflicto con la tradición positivista, que es en su época la última versión secularizada de lo que se ha llamado «sentido lineal de la historia», para la cual se da un desarrollo continuo de la Humanidad. Consecuente con estos puntos de partida es su negación de la historia universal, sustituida ya por una fisionomía y morfología de las culturas. Historia griega, romana, medieval y moderna, son conceptos que si responden a algo, responden a lo occidental, como si todo el pasado gravitase sobre el futuro y apuntase a él. Frente a esta noción simplista Spengler propone una noción de historia que 
se mueve por ciclos definidos, observables e independientes, propios de las culturas. Los movimientos cíclicos de la historia no son las naciones, estados, razas o acontecimientos, sino las altas culturas. Éstas no son comparables, ni lo son sus parámetros, ni sus sistemas políticos, formas económicas o tradiciones: nada entre ellas es conmensurable. Son por tanto ilusorios y artificiales todos los sistemas políticos que pretendan para sí un carácter «universal». ${ }^{4}$ Nuestro Ortega hablará en parecidos términos de «utopismo» e «idealismo». La Ilustración ha de ser trascendida. Nada de ello entraña una novedad absoluta, así como tampoco es del todo original su tipología de las culturas.

Esquemáticamente expuesta, su concepción de la historia parte de que toda cultura posee una trayectoria vital, como los seres humanos. Son organismos vivientes y por lo mismo han de pasar por estadios de nacimiento, desarrollo, plenitud, decadencia y muerte. Comoquiera que todas las culturas anteriores han pasado por esas etapas, la occidental no será una excepción. Es más, podemos detectar en cuál de sus estados nos encontramos actualmente.

No resulta extraño que a la vista de estas concepciones Spengler fuera acusado de profeta casándrico: termina de escribir el libro al final de la primera guerra mundial y al comienzo de una era de estabilidad que pensó que se cerraría inevitablemente al final del siglo o comienzos del XXI, con la aparición de la civilización occidental que, aunque pudiera durar centenares de años, no se revitalizaría.

Considera esta ciencia, cuyos métodos son la comprensión artística y la visión poética, como la vocación especial concedida a los hombres del siglo $\mathrm{XX}$ en el momento culminante y declinante de su cultura. Esta visión es, por otra parte, «un signo que delata la cuesta abajo del camino». «Conocemos nuestra historia, moriremos conscientes y seguiremos los estadios de la propia disolución con la aguda mirada de un médico experimentado».

En la interpretación fisonómica de las diferentes culturas presenta Spengler magníficos aspectos que arrojan luz sobre muchos detalles a los que los investigadores especializados habían dedicado grandes esfuerzos con un éxito menor. Su intuición se dirige sobre todo a las culturas del mundo antiguo y

4 A este esquema, «en el cual las altas culturas describen sus órbitas en torno a nosotros como inevitable centro de todo el acontecer mundial», lo llama él el sistema ptolemaico de la historia; mientras que considera «descubrimiento copernicano dentro del ámbito histórico» el nuevo sistema que aparece en su libro, en el cual la antigüedad clásica y el Occidente ocupan un puesto nada preferente frente a las demás altas culturas $(1,20-23)$. No sabe nada de anteriores intentos de entender las culturas como unidades básicas de la vida histórica; destruye la vieja y lineal imagen histórica eurocéntrica; dirige su mirada a las profundidades, a lo común de los fenómenos históricos, no a lo único y singular, y descubre a lo ancho de la tierra las unidades orgánicas de las grandes culturas. 
de Europa, mientras que las constelaciones del Asia oriental y de la antigua América quedan muy desdibujadas en su estudio.

Spengler denomina a la fase tardía de una cultura «civilización». Cree descubrir la sucesión orgánica de cultura y civilización: «la civilización es el insoslayable destino de una cultura» $(I, 41)$. Según la ley de la vida, la niñez desemboca en la ancianidad y el desarrollo en el aniquilamiento. En esta última fase de la cultura, en la cual la vida rural desemboca en la urbanización, toda obra creativa tiende hacia fuera: hombres cerebrales y sin alma desarrollan una eficiencia puramente cuantitativa, y el poder político aparece como imperialismo. El paso de la cultura a la civilización muestra en la antigüedad nuevamente los perfiles más claros. De este modo, la antigüedad se convierte una vez más en modelo del acontecer cultural. Observamos, por ejemplo, en los siglos de influencia romana, la extinción del arte grande y de los grandes sistemas de pensamiento; el intelecto romano aparece en lugar del alma griega y una cosmovisión uniforme resulta obligada por doquier.

Del hundimiento de la antigua extrae Spengler su imagen del fin de la cultura occidental europea, cuya crisis caracteriza con gran agudeza. En nuestro estadio de desarrollo, que corresponde a la época de las guerras civiles entre Mario y Sila, el ejercicio del poder político de la burguesía se halla en peligro y el parlamentarismo representa la hegemonía del dinero. El retroceso en el movimiento demográfico equivale al suicidio de la raza. La degeneración espiritual hace tiempo que comenzó. En el inicio del proceso de pérdida de valores culturales se encuentra Rousseau; el siglo XIX trajo consigo el advenimiento del nihilismo. En la filosofía y la ciencia se ha alcanzado un estado de visible decrepitud: ha quedado cerrado el periodo de la metafísica e incluso en matemáticas no se trata ya más que de redondear y afinar. Por otro lado, «La esencia de toda cultura es la religión; por consiguiente, la esencia de toda civilización es la irreligión» $(1,445)$. Así como es irreligioso el budismo en comparación con los Vedas y el estoicismo comparado con la fe de la época homérica, del mismo modo aparece el socialismo como la fase irreligiosa del sentimiento fáustico de la vida. Esta fe tardía es alimentada por la masa urbana, los lectores de periódicos, la gente culta, los deportistas y la literatura del día: el periodismo es una especie de cura de almas. Si la moral de Occidente está configurada desde siempre por una alta estimación de la acción, por el mando y la obediencia, de modo que en este punto son iguales «Lutero y Nietzsche, los papas y los darwinistas, los socialistas y los jesuitas» $(1,432)$, la moral de la civilización, sutil y científicamente organizada, se presenta como un socialismo ético, como una economía política de cuño imperialista. La versión epicúrea de la moral socialista quiere hacer la vida más fácil y, en cuanto moral plebeya, aspira al bienestar de las masas. 
Desde el primer tomo de la obra principal señala Spengler en todos sus escritos la necesidad de no dejarse ganar por el pesimismo, a pesar de la previa certeza de la decadencia, sino de comprender lo necesario en un consciente «amor fati». La imagen del hombre que aparece en la morfología de la historia universal fue adquiriendo formas cada vez más duras en los años subsiguientes.

\section{SPENGLER: EL HOMBRE Y LA TÉCNICA}

Cuando su atención se centró en la prehistoria y en la etnología, en 1931, en su escrito El hombre y la técnica. Contribución a una filosofía de la vida, Spengler hizo el intento de una antropología filosófica que completara su filosofía de la historia. En el desarrollo general, tal como lo ve ahora, se alza sobre la planta, que sólo en sentido lato es un ser vivo, la vida libre de los animales. El primer escalón de la vida animal se extiende desde el animal primigenio unicelular hasta las aves nadadoras y los animales ungulados; éste es el escalón de los herbívoros, que están dotados de un fino oído y un buen olfato. El segundo escalón -más alto- vive matando a otros animales. Los animales de rapiña son activos y prudentes, dominan con la vista, conocen el poder, la fuerza y la libertad. La fiera no tolera semejantes en su zona, y en ello se basa el concepto regio de la propiedad. De la fiera procede el hombre por una de las transformaciones de índole catastrófica de las que se compone la historia de la vida. Al añadir ahora al ojo la mano humana como instrumento de dominio, la técnica se vuelve en el hombre consciente, personal e innovadora.

Con el ser humano se da ya el habla y la acción planificada en el grupo, en la familia, en la tribu y en el pueblo. Hay un pensamiento emprendedor, surge un sentimiento indómito de poder y la lucha se comprende como el sentido de la vida. Fuertes personalidades dominan el campo de la lucha con grupos organizados a su servicio. En la sociedad humana el derecho es siempre el derecho del más fuerte y la historia, la historia de la guerra. ${ }^{5}$

Incluso la fe en el progreso de la humanidad es rechazada despectivamente como una cobardía y las consecuencias de esta antropología para el hombre de nuestro tiempo se derivan con inflexible rigor. «Nosotros hemos nacido en esta época y debemos andar hasta el final el camino que nos ha sido asignado. No hay otro. El deber exige mantenerse en las posiciones perdidas, sin esperanza y sin salvación».

5 Pues -se afirma con todo aplomo-: «El hombre es un animal de rapiña. [...] Sólo que la solemne sociedad de los filósofos idealistas y otros teólogos no tuvo la valentía de confesar lo que en secreto se sabía muy bien. Los ideales son cobardías... ». 
¿Cuál es el sentido que la técnica tiene en la vida? 6 Los idealistas, a quienes ha faltado el sentido de la realidad, la han considerado ajena a la cultura, mientras los materialistas, carentes del sentido de la profundidad, hacen de ella un simple instrumento. Para el «tacto fisiognómico», la facultad que nos permite penetrar en el sentido de todo acontecer, ${ }^{7}$ la esencia de la técnica, empero, no es técnica, como dirá Ortega: no debe partirse de la técnica maquinista ni de la suposición de que la construcción de máquinas y herramientas sea su verdadero fin (p. 14). Es un fenómeno antiquísimo y universal, que trasciende al hombre y penetra en la vida de todos los animales. Al animal, frente a la planta, le es inherente afirmarse frente a la naturaleza. «Sólo partiendo del alma puede descubrirse la significación de la técnica» (p. 15). La libre movilidad de los animales es lucha, táctica de la vida, que decide si el destino de esa vida es padecer la historia de los demás o ser historia para los demás. Técnica equivale a táctica de la vida, y vida significa lucha.

Por eso no debe comprenderse a partir de la herramienta, sino de su uso. Se trata de la lucha, no de las armas. Hay una técnica del león, como una técnica de la diplomacia y una técnica lógica. Junto a fenómenos tales como la economía, la guerra y la política, son aspectos de la vida única activa, luchadora, llena de alma.

La vida implica la muerte. El hombre, a diferencia del animal, liberado de las cadenas del aquí y el ahora, lanza su meditación hacia el ayer y el mañana y conoce la muerte. No es fácil soportar la transitoriedad de la vida, pero es la forma de todo lo real. Es efímera la vida del individuo como lo es la de los pueblos, todo se sumerge en el olvido. Nuestra historia, comparada con la del mundo vegetal, animal etc., es muy breve. Nuestro ascenso y descenso, de pocos milenios, carece de importancia en el destino de la tierra. Para los hombres del siglo XX la propia capacidad de percibir la historia y escribirla es un síntoma de que se dirige hacia el abismo. El destino nos condena a la lucha y esa lucha es la vida, «lucha que brota de la voluntad de poder; lucha cruel y sin tregua; lucha sin cuartel ni merced» (p. 18).

El hombre es un animal de rapiña. Su destino es la depredación, pertenece al grupo de los animales cuya vida consiste en matar, una vida que mata y muere. La razón de ello reside en su necesidad de afirmarse venciendo. Los esclavos de la naturaleza, los herbívoros, están dotados de la capacidad de olfatear, mientras que es propio de los señores acechar. El animal de rapiña es enemigo de todo el mundo, porque el mundo es su propiedad. Y si efectivamente en la naturaleza se dan los esclavos y los señores, se dan en ella dos sentidos

6 Cf. El hombre y la técnica y otros ensayos. Trad. Cast. Manuel García Morente. Espasa Calpe, Madrid, tercera ed., 1967, p. 11.

7 Cf. La decadencia de Occidente, Vol. I, cap. II. 
morales contrapuestas, una ética del animal rapaz y una ética del herbívoro, que representan dos destinos diferentes que, en su simplicidad, revelan la táctica de toda la vida. El destino del herbívoro es un destino que se sufre; el del animal de rapiña es ser.

La vida es imposible sin lucha y la lucha puede ser vista como mísero destino de adaptación, pero vista por Nietzsche es lujo y ennoblecimiento, y «el hombre, en su destino, es decir, por su alma, es un animal de rapiña» (p. 24, nota). «... La táctica de su vida es la de un animal de rapiña, magnífico, valiente, astuto, cruel. Quiere ser señor desde que existe» (p. 25).

Para este creador de su propia táctica vital, producto de mutaciones y catástrofes, la mano es un arma y una herramienta, clave de toda la antropogénesis. El hombre es un creador que «hállase en irreconciliable oposición al mundo entero [...] La suya 'es el alma de un rebelde' (p. 32), enajenado de la naturaleza, contrapuesto a ella, antinatural».

\section{SPENGLER: TÉCNICA DE LA DIRECCIÓN Y TÉCNICA DE LA ACCIÓN}

En paralelismo con la naturaleza, en el mundo humano hay, según Spengler, dos clases de técnica que corresponden a dos clases de hombres, que se distinguen por sus aptitudes: hay una técnica de la dirección como hay una técnica de la ejecución. Hombres nacidos para mandar y otros nacidos para la obediencia, sujetos unos, objetos otros de la práctica política y económica. Esta es la forma fundamental de la vida humana. La «diferencia de rango existe absolutamente; y en las épocas y en los pueblos sanos es reconocida por todo el mundo como un hecho, aun cuando en los siglos de decadencia la mayoría se esfuerce por negarla o no verla». Quien cultiva su propia individualidad contradice a la masa, se sustrae a la nivelación espiritual, elude la acción del número (p. 48). Su protesta lo enfrenta al hombre de la masa y la tensión entre los dos grupos humanos crece. Desprecio desde arriba; envidia desde abajo:

Dilátase en el mundo actual una soledad desértica del alma, una desconsoladora nivelación, sin altos ni bajos, que despierta encono contra la vida de los dotados, de los que han nacido creadores. No se quiere ya ver, no se quiere ya comprender que el trabajo director es el trabajo más duro y que de él, de su logro, depende la propia vida. Se siente sólo que ese trabajo hace feliz, que llena y enriquece el alma, y por eso mismo se le odia (p. 60).

Por otro lado, «La creación se subleva contra el creador. Así como antaño el microcosmos-hombre se sublevó contra la naturaleza, así ahora el microcosmos- máquina se subleva contra el hombre nórdico. El señor del mundo tórnase esclavo de la máquina» (p. 60). « [...] [R]eúnese una masa humana de enormes proporciones, masa que se ha disciplinado en la técnica maquinista 
y trabaja para ella y vive de ella [...]. Frente a las masas de manos ejecutoras, que son lo único que la desfavorable 'mirada del pequeño' percibe, resulta ya desconocido y desestimado el creciente valor de la labor directora, que ejecutan unas pocas cabezas creadoras» (p. 61). Lo que Spengler anuncia con tono apocalíptico es que [...] iníciase la sublevación de las manos contra su destino, contra la máquina, contra la vida organizada y, al fin, contra todo y contra todos [...]. Pero la ‘masa' no es más que una negación: la masa niega el concepto de la organización; la masa no es algo que por sí mismo sea capaz de vida» (p. 65).

\section{La valoración orteguiana de Spengler}

Las últimas afirmaciones del autor alemán me parece que se hallan en plena sintonía con el diagnóstico orteguiano. ¿Cuál es su valoración que hace Ortega de la obra de Spengler? Si bien retiene éste la importancia de concepciones spenglerianas como la de «sinfronismo» en su Filosofía de la historia (II, 167 ${ }^{8}$ y las homologías entre acontecimientos muy alejados entre sí en el tiempo y el espacio (II, 511), declara en 1926 (II, 599-600) que le interesan mucho más que sus grandes ideas sus «atisbos subitáneos» que iluminan trozos particulares del proceso histórico. Es un autor que en su reflexión sobre la distinción entre la «cultura» espontánea y la «civilización» sin vigor histórico, no hace sino enunciar una idea «bastante ilusoria» y que en ocasiones no hace sino «levantar la caza a destiempo, sin madurez ni mesura» (II, 613). En su «Prólogo» a la traducción española de La decadencia de Occidente escribe incluso que esta obra, que contiene una filosofía de la historia, la «peripecia intelectual más estruendosa de los últimos años», no es tan original como presume su autor, si bien ha ejercido sobre ellos derecho de cuño (VI, 309-311). En cualquier caso, la mayoría de los temas principales a él le son ajenos. Son ideas que preexistían incluso en el ambiente, «aunque él haya sabido darles una expresión original, prominente y hasta un poco frenética», como dice en otro lugar (III, p. 299).

No obstante estas afirmaciones críticas, Ortega comparte con Spengler una intención de análisis crítico de la situación actual de la sociedad europea, así como el deseo de pensar el futuro, temas que aborda desde una perspectiva biologista. Así, afirma en El tema de nuestro tiempo que por ser la existencia humana «vida», proceso interno en que se cumple una ley de desarrollo, es posible la ciencia histórica. Comprendemos históricamente cuando vemos una época surgir necesariamente de otra anterior, no merced a una necesidad física, matemática o lógica, sino psicológica. Por eso la profecía hace uso de la misma operación intelectual que la comprensión del pasado. En ambos casos

8 Citaré según la edición de las Obras completas en Revista de Occidente y Alianza Editorial de 1983. El volumen se indicará en números romanos y la página en arábigo. 
reconocemos una misma curva psicológica. «Cuando el sentido histórico se perfecciona, aumenta también la capacidad de previsión». Eso sí, como añade en nota, «Esta doctrina de una posible anticipación del porvenir no tiene apenas contacto con el 'profetismo histórico' que recientemente ha proclamado $\mathrm{O}$. Spengler» (III, p. 154), quien funda su profetismo en una contemplación de las vidas históricas desde fuera de estas, consistente en una comparación intuitiva de su morfología. Ortega, al contrario, propone el pronóstico histórico desde dentro de una vida y no por comparación de ésta con otras (III, p. 154-155). Más adelante negará que se haya trazado por completo el círculo humano y es en ello en lo que el libro de Spengler se equivoca. Y aclara: «yo no lo he leído, pero lo he ojeado y me parece que esas semejanzas cíclicas encontradas por el autor en el desarrollo de diversas culturas, aun suponiendo que sean ciertas, no contradicen una evolución de la humanidad hacia estados siempre nuevos» (III, p. 269).

Ortega reconoce que cuando Spengler hace de las culturas las auténticas protagonistas de la historia, da forma a una intuición del pluralismo universal que es una gran innovación de la cultura europea, a la que proporciona un fundamento metafísico. Gracias a éste, la ciencia histórica, en vez de tropezar como un una roca de irracionalidad con la peculiaridad de los pueblos, que son de hecho irreductibles, hace de ella el punto de partida.

Pero Spengler ha ignorado una dimensión decisiva del progreso histórico. En efecto, lo que de veras necesitamos es una psicología de la evolución capaz de reconstruir las diferentes estructuras de la conciencia humana en cada época. Y no se trata sólo de sus contenidos y creencias, sino de algo más profundo, que sólo hallaremos en su aparato conceptual mismo con sus categorías. Una vez detectada la personalidad y las diferencias de cada cultura procede extraer consecuencias de orden estimativo, conquistando nuevos mundos espirituales, propios de cada cultura, cada una con su genialidad, de modo que «cada época, cada pueblo, será nuestra maestra en algo, será en un orden u otro nuestro clásico» (III, p. 311-312).

Aún hay otra diferencia radical con la obra de Spengler, que subraya Ortega, definiendo frente a él su propia posición: Spengler muestra la relatividad de las culturas sin advertir que ello «es hacer faena absoluta». En efecto, la historia, al reconocer la relatividad de las formas humanas, se desprende de la relatividad, porque ve cada forma surgir en una cultura determinada, no necesariamente la occidental sin que ello le reste carácter absoluto. El descubrimiento de una verdad es siempre un hecho con fecha y localización, pero la verdad descubierta es «ubicua y ucrónica». Y la historia es precisamente el intento de superar la variabilidad de la materia histórica (III, 312-313).

Más allá de las culturas hay un cosmos que el hombre vislumbra en la historia, en un esfuerzo milenario en el que colabora cada pueblo, que actúa 
entonces como un órgano gigante que consigue percibir algún trozo de ese trasmundo.

En cualquier caso, Ortega aprecia en Spengler, en primer lugar, una sensibilidad que trasciende el idealismo y el progresismo del siglo XIX, para cuestionar la dirección misma del curso histórico y su deriva hacia la decadencia; en segundo lugar, su abandono del eurocentrismo (la revolución copernicana de que habla Spengler) y su atención a la diversidad de las culturas y su carácter inconmensurable. ${ }^{9}$ Libera así a la comprensión histórica de su carácter tradicionalmente limitado. Ahora bien, «esta reflexión que nos liberta de la limitación histórica es precisamente la historia» (III, p. 314).

\section{ORTEGA: REBELIÓN DE LAS MASAS, DESERCIÓN DE MINORÍAS}

En el diagnóstico crítico de la Modernidad contenido en La rebelión de las masas Ortega se mueve no sólo en el ámbito de lo psicológico, sino que busca y subraya la trabazón de las dimensiones política, social y fundamentalmente técnica que definen la época presente, así como las consecuencias sociales más evidentes del hecho del surgimiento de las masas en su relación con la democracia. El creciente predominio de las masas es paralelo a la inflación tecnológica contemporánea, hasta el punto de merecer una reflexión que destaque su íntima conexión y el carácter decisivo de su significación histórica. Ortega no fue el único ni el primero en ver la magnitud del fenómeno ni en apreciar su significación.

En 1906 había visto la luz la obra de Georges Sorel Reflexiones sobre la violencia ${ }^{10}$ libro en que se exaltaba el mito, la violencia y la insurrección, en términos que se dirían inspirados en Marx, Nietzsche y Bergson. La obra aparece en un momento alejado aún de la «Gran Guerra» tanto como la revolución bolchevique, pero en ella se exalta la violencia, se maldice la «democracia plutocrática» y se proclama que acabar con «el orden burgués» es la sagrada tarea del proletariado, «héroe de un drama cuyo éxito final depende de su energía, de su celo y de su capacidad de sacrificio y elevación», comprometido en una guerra santa contra la explotación. Ahora bien, si ésta es la misión del proletariado, en

9 Como se ha apuntado más atrás, Spengler permanece anclado en un eurocentrismo para el que «Historia universal» equivale a «historia occidental», siendo las demás historias objeto de apresurada visita en busca de alguna homología superficial, anécdotas arrancadas del conjunto o de corroboraciones laterales consideradas significativas únicamente desde la arbitrariedad. Pero no sólo eso: el libro parece defender y sostener una óptica nacionalista «teutona», cuya vecindad con el nazismo también hemos señalado. Por último, asegura y cree demostrar que no existe una cultura universal pero da pruebas de ser capaz de abarcarla entera e incluirla en una única síntesis, que asemeja una enciclopedia en la que todo parece estar presente.

10 Trad. de Fl. Trapero. Alianza Ed., Madrid, 1976. 
rigor corresponde a una minoría que, interpretando a la masa pero separándose de ella, propiciará la huelga general y aun las violencias más contundentes, en una suerte de permanente «gimnasia revolucionaria». Por otro lado, el libro, precursor de acontecimientos posteriores, servirá de inspiración a Mussolini. Un libro revolucionario que invoca a las masas pero cree en una élite; obra de un hombre de izquierda que sirve a las tendencias de ultraderecha. Mito y violencia: una síntesis que inspiró nefastas experiencias totalitarias.

Sorel da fe del hecho de que la socialdemocracia reformista ha vaciado de sentido el combate proletario. La burguesía está dispuesta a pagar de su bolsillo su propia supervivencia y espera así hacer más difícil la propagación de las doctrinas del odio, capaces de provocar la revolución, en la que ya no piensan los socialistas parlamentarios, que han olvidado la procedencia bélica de muchas de las ideas que dicen defender; por su parte, la burguesía se deja fácilmente despojar, siempre que se la atemorice con la revolución y los esfuerzos por eliminar la hostilidad existente no han tenido tanto éxito como el que creen sus impulsores. Se ha hecho tarde para no prestar gran atención a los obreros; si los gobiernos subvencionan a partidos y periódicos, los obreros pueden infundir miedo porque « [...] el factor más determinante de la política social es la cobardía del gobierno». Es preciso « [...] aprovecharse de la cobardía burguesa para imponer la voluntad del proletariado». La violencia obrera y la acción tumultuaria son el medio más eficaz para obtener concesiones. Tal es «el método directo y revolucionario». La burguesía cobarde persigue la quimera de una paz social basada en la cobardía de quien se sabe condenada a muerte. ${ }^{11}$

Unos diez años antes que Sorel, Gustave Le Bon había detectado el imponente fenómeno de la «rebelión de las masas», tras la que advirtió el hecho de las aglomeraciones y la dilución en ellas de la personalidad individual y consciente, el crecimiento del poder del hombre masa alimentado, desde fuera, por lo quebradizo y apocado del poder político, y, desde dentro, por su capacidad de hacerse fuerte precisamente en su debilidad: un inmenso poder de ceder a las sugestiones, adueñarse del estado, menospreciar la cultura.

Y quince años después de aparecido el libro de Sorel, en 1921 escribió S. Freud su Psicología de las masas, ${ }^{12}$ en cuya "Introducción», en «El alma colectiva según Le Bon», encuentra Freud un punto de partida para la conexión

11 Lo innovador en Sorel son los términos en que en su obra se defiende el valor de los mitos y el combate mismo, su rechazo de los «mitos burgueses» (libertad, igualdad, fraternidad, progreso) y su exaltación de los «mitos revolucionarios», anunciando que a los socialismos utópico y científico, sucederá el «socialismo mítico», doctrina apoyada en consignas de combate.

12 Sigmund Freud, «Psicología de las masas», en Obras completas, Vol. VII. Trad. Luis López Ballesteros, Biblioteca Nueva, Madrid, 1974; Alianza Ed., Madrid, 1972. 
de la psicología individual y la colectiva, más similares de lo que parecen a una psicología superficial.

Es un hecho que el individuo incorporado a una masa piensa, siente y obra de un modo completamente inesperado o al menos inédito ¿En qué consiste semejante modificación psíquica? Por diferentes que sean los individuos que la integran, al hallarse transformados en una multitud se dotan de una especie de alma colectiva, que les hace pensar, sentir y obrar de manera por completo distinta de como sentiría, pensaría y obraría cada uno aisladamente. Le Bon no se había planteado la cuestión de qué es lo que los enlaza entre sí, que sería precisamente lo que caracteriza a la masa, para pasar a detallar las modificaciones que experimenta el individuo. Recurrió al papel preponderante del inconsciente en el funcionamiento de la mente, a los residuos ancestrales que «constituyen el alma de la raza», en la que se diluyen las adquisiciones individuales. Cuando surge «lo inconsciente social», lo heterogéneo se funde en lo homogéneo. La superestructura psíquica cede su lugar a la base inconsciente común a todos y el individuo, integrado en una masa, adquiere el sentimiento de una potencia invencible que le permite precisamente ceder, ser dócil a sus instintos, a los que se abandona tanto más gustoso cuanto por ser una multitud anónima, se siente, en consecuencia, irresponsable. Ello lleva a Freud a la afirmación de que al individuo incorporado a una masa le parece natural suprimir las represiones de sus tendencias inconscientes. De este modo, los caracteres aparentemente nuevos que entonces manifiesta son precisamente exteriorizaciones de lo inconsciente individual, «sistema en el que se halla contenido en germen todo lo malo existente en el alma humana» (p. 14). «Por el solo hecho de formar parte de una multitud, desciende, pues, el hombre varios escalones en la escala de la civilización. Aislado, era quizá un individuo culto; en multitud, un bárbaro. Tiene la espontaneidad, la violencia, la ferocidad y también los entusiasmos y los heroísmos de los seres primitivos» (p. 16).

Pero tanto en Spengler como en Ortega, el fenómeno técnico es inseparable de esta ascensión del nuevo tipo humano que se venía avistando en las obras que acabo de citar, y que Ortega lleva a un nuevo planteamiento. Dice C. Mitcham que Ortega fue el primero de los filósofos profesionales que se ocupó de la técnica y que incluso fue más sensible ante este fenómeno que Heidegger y Ellul. Los dos principales lugares en que escribe sobre la técnica son La rebelión de las masas, de 1930 y la Meditación de la técnica, de 1939. La obra de Jacques Ellul La técnica o la apuesta del siglo y la de Heidegger La pregunta por la técnica, no aparecerán hasta 1954. Los libros de Kapp y Dessauer (Flosofía de la técnica, de 1926) y el propio trabajo de L. Mumford (Técnica y civilización), sin embargo, sí son anteriores a la Meditación de la técnica, lo que no impide a Ortega echar en falta una bibliografía «aprovechable» sobre el tema cuando escribe su, por otra parte, poco apreciado trabajo. 
Si las conclusiones de La rebelión de las masas, se mantienen en un plano predominantemente sociológico, las consideraciones de Meditación de la técnica, escrito mucho menos conocido, se mueven en un plano antropológico. Publicado en 1939, se trata de un texto hecho a base de artículos de periódico que a su vez reproducen un curso. Un texto, pues, poco elaborado, perteneciente al género del ensayo y la meditación. ${ }^{13}$

La rebelión de las masas es un libro amargo y lúcido, que presiente importantes dificultades, justo en momentos en que las grandes esperanzas de su autor para su país iban a proceder de Europa. Libro alarmado, aunque no alarmista, coincide parcialmente con las apreciaciones de G. Le Bon: las aglomeraciones, la personalidad mística de los conjuntos humanos e incluso sus creencias, el narcisismo colectivo, la homogeneidad de la masa pasional, la constitución de un bloque de odio y nivelación, el aumento de la homogeneidad y precisión en la percepción de las cosas, su propensión a adueñarse del Estado al que llegan y desde el que mandan sin razón...

También me parece suscribiría la conclusión de Le Bon: la civilización nacerá con un sueño y evolucionará desde la acción creadora a la destructiva. La vejez será el síntoma del debilitamiento del ideal, seguido por el particularismo y la falta de cohesión, que en parte se tratará de paliar con el recurso al Estado. La pérdida del alma determinará el retorno de las masas, a la barbarie. «Passer de la barbarie à la civilisation en poursivant un rêve, puis décliner et mourir dès que ce rêve a perdu sa force, tel est le cicle de la vie d'un peuple» (p. 65). ${ }^{14}$

13 Por otro lado, es una obra de madurez, cuyos presupuestos se hallan presentes en Meditaciones del Quijote, si bien la preocupación española del texto de 1914 se ha extendido ahora a problemas no únicamente españoles. En su edición de 1939, la meditación... está precedida del texto titulado Ensimismamiento y alteración y se incluye hoy en El hombre y la gente. El mito del hombre allende la técnica es una conferencia pronunciada en el congreso de Darmstadt de 1951 y es una reelaboración de la Meditación. El trabajo En torno al coloquio de Darmstadt. 1951, fue publicado un año después. Al capítulo IX de La rebelión de las masas titulado «Primitivismo y técnica» se refiere ortega explícitamente en la página 331 de la Meditación.

14 La Psychologie des foules, se publicó en 1895. En las obras completas de 1983 figuran dos menciones a Gustave Le Bon, ambas en El genio de la guerra y la guerra alemana, de 1915 (O.C., vol. II, pp. 214n. y 222n.) En el primer caso, trae a colación las afirmaciones del francés sobre el problema de las relaciones entre lo económico y la superpoblación expuestas en su libro Enseñanzas psicológicas de la guerra mundial, 1916, a las que refuta; en el segundo, en la página 222 de la misma obra y también en nota, no es relevante para nuestro tema. Ortega tuvo en su biblioteca varios libros de Gustave Le Bon, pero la Psychologie des foules (Reedición en P.U.F., París, 1963) no figura entre ellos. Debo esta información a la amabilidad de Da Ascensión Uña, bibliotecaria de la Fundación Ortega y Gasset. 
Le Bon ha advertido la trascendencia del fenómeno, manteniéndose en un plano psicológico que destaca la docilidad a las sugestiones y la emergencia de una energía racial, suficientes para producir una petulante irresponsabilidad hacia la cultura; como Freud, su análisis profundiza en el lado psicológico y coyuntural, postergando lo cultural y económico. Ambos parecen observar en el fenómeno del hombre masa un carácter sólo coyuntural y no estructural ni definitorio de la decadencia de la cultura, como me parece ser el caso de Ortega, para quien la crisis desborda y trasciende el plano de lo psicológico y coyuntural, y atiende a las formas de existencia que la humanidad adopta en esta hora decisiva en la que la vida es vista como esfuerzo y voluntad, aceptación y riesgo, o bien como gregaria aceptación de la existencia y como rechazo de lo excelente.

La insistencia de Sorel en la violencia no es mera manifestación de su actitud política revolucionaria sino que forma parte de una proclama que obsequia a las masas con el único mensaje que aquellas se muestran dispuestas o capaces de escuchar: el halago del sentimiento de odio y revancha ante la injusticia, pero también ante toda superioridad. Ni Sorel, ni Le Bon, ni Freud toman en cuenta, por otra parte, el otro lado del problema, la otra vertiente del drama europeo: la «vacación» o deserción de las minorías.

Ortega cree que vivimos la pleamar de las masas, su «invasión horizontal». Pero la rebelión de las masas es sólo una parte de la crisis, su costado más llamativo. La deserción de las minorías es la otra arista de un problema ya muy grave. «Principios hechos para destruir no pueden servir para construir» -parece decir Ortega siguiendo a Comte, y como él, nostálgico de un «poder espiritual» europeo, que hoy sólo detenta la prensa-; ahora bien, los periódicos, por su naturaleza misma, son el lugar donde más pronto y más claramente se manifiesta lo falso de cada época (II, 730).

La publicación de la obra de Julien Benda La traición de los intelectuales prácticamente coincide en el tiempo con la de La rebelión de las masas y parecerían títulos y obras complementarias. Benda denuncia una deserción de los intelectuales visible en un doble sentido: ${ }^{15}$ en primer lugar, una traición en lo político, que se plasma en su respaldo a posiciones irracionalistas, individualistas o fascistas: el yo, la nación o la clase han sido otras tantas suplantaciones irracionalistas de la razón. Pero en segundo lugar el ensayista francés habla de una traición propiamente filosófica: la infidelidad al pensamiento occidental tal como nos ha sido enseñado por la tradición que nos constituye y a la que permanece plenamente leal, una fidelidad desde la que denuncia la traición. La traición, pues, ha sido doble: una traición política y otra intelectual (Cf. pp.

15 Manejo la edición de La Galaxia Gutenberg y Círculo de lectores. Trad. R. Barraquero, Barcelona, 2008. 
42 y 43 y ss.). Benda y Ortega coinciden en la apreciación de la gravedad del hecho y sus dimensiones, la inquietud ante el futuro, el avance de las masas y la deserción de las minorías. Como veremos, no son menores las divergencias.

Julien Benda ha advertido con claridad la presencia de dos elementos igualmente importantes en la obra de G. Sorel: la insistencia en la potencia del mito y el irracionalismo de su reivindicación de la violencia. Se ocupa del autor de las Reflexiones sobre la violencia poniendo de manifiesto lo nocivo de sus proclamas. Pero el núcleo central de su obra me parece éste: el intelectual moderno, lejos de proponerse atenuar las diferencias entre los hombres de distintas clases o naciones, y reforzar su sentido de la pertenencia a la Humanidad, ha acentuado las primeras en detrimento de la segunda, siguiendo así las consignas de Sorel. El resultado es el incremento del sentimiento de odio.

Si en tiempos de Grecia el pensamiento buscaba la verdad, el siglo XX ha presenciado la orientación de este mismo pensamiento en el sentido de la eficacia política: si en el pasado estuvo representado por la figura del pensador griego, la actualidad se halla bajo el dominio del intelectual alemán. El intelecto griego buscaba la permanencia e identidad de la verdad ajena a los avatares de los sucesos del mundo y la misma materia. Nuestra época, por el contrario, ha asistido a la defensa de una suerte de movimiento ascendente de la materia con la que el intelecto tendría que fundirse, sustrayéndose a un mundus intelligibilis abstracto y alejado de la vida. La razón es, en efecto, constitutivamente «estéril», y por sí mismo el intelecto no tiene un objetivo práctico. La razón se orienta de modo inutilitario únicamente a la búsqueda de la verdad. Pero la era de la política desconoce el sentido de la verdad y sólo persigue en la razón aquello que puede conducir al éxito, atraer voluntades, resultar persuasivo, arrastrar más que convencer.

La minoría intelectual quizá o tendría podría decir: mi reino no es de este mundo. Pero lo novedoso es precisamente la traición a su papel. Benda recurre (pp. 123-6) al contraste entre el ejemplo de Goethe, y su apego a la abstracción, con el de los caracteres del nuevo intelectual, cuya influencia y éxito son otros tantos signos de su traición. Como dice más adelante, (p. 202), los intelectuales se han vuelto masa: el «derecho del número» se ha impuesto sobre ellos, hecho inédito y alarmante de «la historia moral de la especie humana», el predominio de la voluntad sobre el desinterés de una razón en lo que tiene de universal (p. 189).

Las consideraciones de Julien Benda se mantienen en un plano ideológico: la proclividad de los intelectuales al racismo, al comunismo y al fascismo suponen toda una traición intelectual. Ortega coincide con el ensayista francés, pero su diagnóstico no le sigue hasta el final. Ya nos hemos referido a un trabajo 
anterior $^{16}$ en el que se ponía de manifiesto el contraste del acercamiento orteguiano el problema del hombre masa con los enfoques de la primera Escuela de Frankfurt, por un lado, y el de Heidegger, tal como lo ve Pedro Cerezo, por el otro. Según este análisis, nuestro autor, en parte ciego para lo económico y en el fondo leal a la Modernidad, carga en las espaldas del hombre masa la responsabilidad de la crisis, incapaz de apreciar su carácter de mero producto de la misma; sería Heidegger quien habría tomado distancia de la Modernidad, llevando a cabo una crítica no externa sino interna de la misma. Nuestro parecer, sin embargo, es muy otro: lo que distancia a Ortega de la crítica de Julien Benda es precisamente una profundización en la modernidad y en el concepto de intelectual y de la misma razón que, sin arrastrarlo al totalitarismo, le permite aventurar una solución a la crisis.

Para Ortega una sociedad es una masa regida por una minoría ${ }^{17}$. El eclipse de la minoría y el declive de su función rectora son una manifestación de la debilidad esencial de una «civilización moderna» (Cf. II, 719 y 745-6) en la que prevalecen los derechos sobre las obligaciones y que consiste en medios y no en actitudes últimas, dejando inculto el fondo de la existencia (II, 720), aquello que en la vida del hombre es lo absoluto o a través de lo cual ésta arraiga en lo absoluto. Es esta nuestra civilización, superficial, que fomenta la indiferencia y la incapacidad del compromiso, en la que no cabe la excelencia.

La deserción de las minorías se da en un doble contexto. En primer lugar, su claudicación ante las masas durante el siglo XIX consistió en halagarlas. A medida que la democracia fue evolucionando, en una primera fase, la democracia fue entendida como la obligación que el hombre tiene de conquistar y ejercitar derechos inalienables. Los intelectuales de su tiempo se enfrentaron a la inmoralidad de las masas incultas desde una moral exigente. En una segunda fase, empero, ya se habla a las muchedumbres únicamente de sus derechos y nunca de sus obligaciones, en la esperanza, quizá, de sellar con ellas un pacto. Como no era posible firmar paz alguna, en un tercer momento, se hostigaron las pasiones y la propensión tiránica de las masas, proclamando a los cuatro vientos sus derechos y ocultándoles todo sentido de la obligación.

La segunda deserción tiene lugar en otro plano, esta vez ajeno a la vida política. Las minorías han desertado porque no han sentido la urgencia de instaurar un nuevo orden espiritual cuando la crisis sustantiva de la «cultura moderna» lo reclamaba. Las minorías intelectuales han vivido para sí,

16 J.M A Atencia, «Ortega y Gasset: Sociología y antropología de la técnica», en J.M ${ }^{\mathrm{a}}$ Atencia y A. Diéguez (eds.), Tecnociencia y cultura a comienzos del siglo XXI. SPICUM, Málaga, 2004.

17 Cf. «Para los niños españoles», «Misión de la Universidad», «Sobre la enseñanza clásica», «Misión del Bibliotecario», España invertebrada, El espectador,La rebelión de las masas. 
sin hacerse cargo de su función directiva, recluyéndose en el especialismo. Si antes las minorías encarnaban y ejercitaban el pequeño papel del espíritu en la historia, ahora han dimitido. Y cuando la masa no es dirigida «gravita a donde la lleva su peso bruto; por eso es ésta una de las épocas [...] en que la historia va más a la deriva...» (II, 735).

Los intelectuales, barridos del paisaje social, no son ya ni siquiera escuchados. Y la crisis presente no consiste en que no se obedezca a principios superiores, sino a que no los hay. Ha comenzado en el mundo occidental una empresa que desde hace dos mil quinientos años nunca se había intentado, a saber, organizar la vida humana prescindiendo del intelectual. Esto a Ortega ni le sorprende ni le espanta, y propone al intelectual soledad y recogimiento porque son «el modo más perfecto de ser intelectual y, por tanto, el modo más fecundo de colaborar en la vida humana general [...]». El intelectual es muy esencialmente vox clamantis in deserto (XII, 248-249). De hecho -dice- "yо no espero que se me haga caso».

Pero la vida humana padece horror vacui y necesita de principios intelectuales: ya no puede contar con la Iglesia, y el Estado se halla dominado por la opinión pública; la Universidad se halla en poder de la ciencia. Sólo queda la prensa (IV, 352 y ss.), cuyo rango es «inferior». Los periodistas (Ortega reconoce que tal vez él mismo no es más que uno de ellos) son «una de las clases menos cultas de la sociedad presente. Pseudointelectuales chafados llenos de resentimiento y de odio hacia el verdadero espíritu», definidos por el apego al presente momentáneo sin perspectiva ni arquitectura. «Lo real es de cierto pura actualidad; pero la visión periodística deforma esta verdad reduciendo lo actual a lo instantáneo y lo instantáneo a lo resonante». Y añade: «No poco del vuelco grotesco que hoy padecen las cosas [...] se debe a ese imperio indiviso de la Prensa, único 'poder espiritual'» (p. 353).

La técnica ha hecho posible un enorme aumento de posibilidades vitales de los hombres, pero también la nivelación de todos, la confianza irresponsable en la técnica misma y en el futuro, se convierte en razón y la suplanta..., Ortega denuncia el modo como la abundancia de instrumentos va más allá de la sensibilidad humana y las enormes posibilidades ahogan la imaginación creadora. Para Ortega, en fin, la tecnicidad triunfal asfixia la imaginación y la facilidad sofoca los deseos (V 344).

Junto a un crecimiento fabuloso de posibilidades y de medios, Europa presenta síntomas de una desmoralización radical. Al lado de una ingente capacidad de realizar cosas, exhibe un paralelo y no menos llamativo desconocimiento de aquello que merece la pena. Una sociedad de la abundancia a la deriva, perdida en cuanto a la percepción del sentido de la existencia. Éste es el núcleo esencial de La rebelión de las masas: la cultura europea moderna ha dejado de ser capaz de orientar la vida de los hombres. Las masas viven una 
ilusoria suficiencia y un hermetismo cerril, mientras las minorías desertan. El hombre-masa atribuye un mero carácter natural a la cultura (IV, 181 y 202), desconociendo la dificultad de su origen y la dignidad de sus principios. Su mentalidad y su actitud son las de un «bárbaro vertical» (IV, 189-190): el primitivismo y la falta de sentido cultural. Ortega detecta el peligro de un vaciado de contenido de la civilización europea, peligro que aumentará con su propio desarrollo (IV, p. 203).

\section{ORTEGA: TÉCNICA Y HOMBRE}

En el diagnóstico crítico de la Modernidad llevado a cabo en La rebelión de las masas, Ortega subraya las consecuencias sociales más evidentes del hecho del surgimiento de las masas en su relación con la democracia y la tecnología, que han hecho posible el enorme crecimiento de la población y su bienestar material. Han crecido extraordinariamente las posibilidades vitales. Ahora bien, en esta nueva situación no dejan de aparecer peligros. Paralelamente, se dan en la actual sociedad otros fenómenos que al menos en parte vienen propiciados o han sido hechos posibles por la tecnología.

En primer lugar, lo inédito de la situación hace que la tradición quede desbordada y no sea ya posible encontrar en ella elementos para orientar el futuro. Además, el producto característico de la nueva situación, el hombre masa, es indócil a las minorías y afirma la nivelación total. En tercer lugar, a este tipo de hombre corresponde una concepción de la vida como vida sin esfuerzo, falta de contención, ausencia de sacrificio... La vida social se ha teñido de una hiperdemocrática nivelación, correlativa de una creciente atrofia de la capacidad humana de superación.

Por otro lado, la técnica suplanta a la razón: la razón técnica (la razón instrumental, dirán los frankfurtianos), tiende a suplantar a la razón vital: se ha hecho ella misma razón y aspira a regir los destinos humanos; el modelo ilustrado de racionalidad sucumbe ante la racionalidad limitada al modelo de las ciencias físico matemáticas.

Además, se extiende la convicción de que el avance técnico por sí mismo contiene la llave de un futuro siempre mejor. Ha propiciado el progresismo, la ideología de la irresponsabilidad, la idea de que el futuro nos reserva lo mejor sin que tengamos que ser nosotros quienes forjemos ese futuro, constitutivamente incierto. Es así como la historia queda vacía de sentido, desactivada: el futuro está decidido y está decidido por la técnica.

En fin, si la cultura había sido siempre disciplina y contención de los propios deseos, el hombre es ahora invitado a no limitarse, a abandonarse a sí mismo y a dejarse llevar.

La técnica, pues, hace posible el aumento de posibilidades vitales de los hombres, pero también la nivelación de todos, la confianza irresponsable 
en la técnica misma y en el futuro, se convierte en razón y la suplanta. Pero, sobre todo, la saturación tecnológica del mundo es causa de una atrofia de la capacidad humana de desear. Ortega denuncia así el modo como la abundancia de instrumentos va más allá de la sensibilidad humana, las máximas posibilidades ahogan la imaginación creadora (por cierto, desconociendo el hecho de la dificultad que sufren aquellos a quienes simplemente deja de lado el progreso). La tecnicidad triunfal asfixia la imaginación y la facilidad sofoca los deseos (V 344).

Si en La rebelión de las masas parte de consideraciones relativas a la psicología del hombre masa y a la crisis de los deseos, en la Meditación de la técnica su objeto es la técnica como dimensión de lo humano. La técnica es parte de la cultura. ¿Cómo se relacionan entre sí la cultura y la naturaleza humana? Ortega sostiene que, por una parte, el hombre es un ser naturalmente técnico pero, por otra, carece de naturaleza.

Para Ortega la cultura es natural y se asienta de un modo no consecutivo sino constitutivo en el ser del hombre. Cuando Ortega dice que el hombre no tiene naturaleza, sino historia (VI, p. 24, 32 y 41), está afirmando que la indeterminación de su naturaleza plantea la exigencia de la determinación por la cultura, que se produce en la historia. Ahora bien, esta realidad cultural sobreañadida a una naturaleza inacabada como aparato ortopédico puesto a un instinto quebrado, esta realidad cultural, el artificio, es, como todo lo que es humano, histórico. ${ }^{18}$

No hubo nada humano antes de la técnica porque el hombre es técnico por naturaleza, porque la técnica pertenece a la esencia humana, y sin técnica no hay hombre. Y la técnica es un modo de ser condicionado por el modo del ser del hombre en la naturaleza. La técnica resume a la naturaleza humana y se inscribe en la cultura y la historia de la vida como correlación de esa misma vida con el mundo, en tanto que elemento de un proyecto vital pre-técnico: pertenece a una vida que es ante todo posibilidad, y que, por tanto, se vincula al deseo, a lo imaginario, al inacabamiento esencial de lo humano. Por eso, y como ahora

18 Los tres estadios en el desarrollo histórico de la técnica responden a tres tipos de deseos humanos y éstos a tres ideas de la vida que se han sucedido a lo largo de la historia, de las que han surgido las necesidades y los deseos : en la técnica guiada por el azar, es concebida como un don de Dios ; la técnica del artesano, fundada en la tradición más que en la invención, y la técnica del técnico, la época del tecnicismo, marcada por la autonomía de la máquina. Luciano Espinosa señala atinadamente que Ortega emplea en su clasificación cuatro criterios diferenciadores : la «cantidad» de técnica en cada momento ; la consciencia de lo que supone, el rango de sus productos (más o menos autónomos) y la especialización profesional a que da lugar. Espinosa los llama, respectivamente «cuantitativo o espacial», «cualitativo o mental», «productivo»y «social». «El conjunto arroja un progresivo alejamiento de lo espontáneo hacia una creatio ex aliquo de un mundo nuevo» que define el curso de la historia (Loc. cit., p. 138). 
veremos, la vida es obra de la imaginación y el mismo hombre es un novelista. Como novelista, tanto como técnico, el hombre es «animal de irrealidades».

Cuando el ser humano empieza a serlo es ya homo faber. Su aparición supuso una innovación de colosales dimensiones en el universo, el surgimiento de un ser que, lejos de adaptarse al mundo, ajusta la naturaleza a sus deseos. La técnica, la adaptación al y del mundo aparecen así como algo si no sobrenatural, sí como praeternatural. La razón de todo ello la resume Ortega bellamente en este texto tardío que reproduzco verbatim:

El hombre es un animal inadaptado, es decir, que existe en un elemento extraño a él, hostil a su condición: este mundo. En estas circunstancias, su destino implica, no exclusiva, pero sí muy principalmente, el intento por su parte de adaptar este mundo a sus exigencias constitutivas, esas exigencias precisamente que hacen de él un inadaptado. Tiene, pues, que esforzarse en transformar este mundo que le es extraño, que no es el suyo, que no coincide con él, en otro afín donde se cumplan sus deseos -el hombre es un sistema de deseos imposibles en este mundo-; en suma, del que pueda decir que es su mundo. La idea de un mundo coincidente con el hombre es lo que se llama felicidad. El hombre es el ente infeliz, y por lo mismo, su destino es la felicidad. Por eso, todo lo que el hombre hace, lo hace para ser feliz. Ahora bien, el único instrumento que el hombre tiene para transformar este mundo es la técnica (VIII, 86). ${ }^{19}$

\section{Concomitancias y Diferencias entre SPEngler y Ortega}

No llegaríamos hasta la afirmación de que se da entre los dos filósofos una solidaridad completa ni que en los planteamientos de Ortega pueda advertirse algún tipo de influencia del autor alemán. Sí, en cambio, es bastante visible una coincidencia en aspectos esenciales de sus planteamientos. De nuevo se vuelve apreciable la impronta nietzscheana que marcó a autores de muy distinta orientación situando sus reflexiones en el ámbito de una meditación sobre la vitalidad.

Es desde esta instalación desde donde Spengler y Ortega parten de la afirmación de que la ciencia positiva se hace una concepción insuficiente de la temporalidad, y, por tanto, de la historia, defendiendo la propuesta de una nueva manera de plantear los problemas a la luz de otra racionalidad, que será la razón vital en Ortega, mientras que el alemán se refiere a un «tacto fisiognómico», por completo ajeno a las exigencias de la lógica. La impugnación de este tipo de racionalidad científica se halla acompañada de una atención muy diferente y matizada a la peculiaridad, a lo concreto e individual, postura desde la que

19 En la conferencia de Hamburgo incluida en Goethe sin Weimar reproduce casi literalmente estas expresiones. 
se estiman ilusorios y artificiales, por ejemplo, todos los sistemas políticos que pretendan para sí un carácter «universal». Nuestro Ortega hablará en parecidos términos de «utopismo» e «idealismo». La Ilustración ha de ser trascendida.

Spengler pone las bases de una ciencia cuyos métodos son la comprensión artística y la visión poética, como la vocación especial concedida a los hombres del siglo XX en el momento culminante y declinante de su cultura. Ortega dedicará buena parte de su vida al desarrollo de la razón histórica.

Es el «tacto fisiognómico» la facultad que nos permite penetrar en el sentido de todo acontecer ${ }^{20}$ y el que pone de manifiesto que la esencia de la técnica no es técnica. En su raíz se halla la vida misma, raíz y fundamento de la cultura, por lo que no debe partirse de la técnica maquinista ni de la suposición de que la construcción de máquinas y herramientas sea su fin esencial. En su meditación sobre la técnica ambos autores trascienden el plano meramente instrumental y su enfoque positivista para ahondar, en primer lugar, en la compenetración del plano prehistórico y antropológico con el metafísico. Se trata, pues, de un acercamiento que hace de la técnica un fenómeno no meramente técnico, por lo que, como dice Spengler, «sólo partiendo del alma puede descubrirse la significación de la técnica».

Esta significación es la «táctica de la vida» en Spengler o la reforma que el hombre impone al universo en Ortega; un elemento que altera la significación misma del «fenómeno humano», destacando su novedad e irreductibilidad al resto de los seres naturales. Pero en el caso del alemán encuentro mucho más destacado el aspecto conflictivo y agónico del puesto del hombre en el mundo, como animal de rapiña, que en el español, que subraya la índole lujosa, superflua, deportiva y creadora del esfuerzo humano. Frente a la vida como lucha despiadada, pues, la vida como stadium, esfuerzo deportivo, jovialidad.

En ambos autores se mantiene la distinción entre vida ascendente y descendente, moral de señores y esclavos, o diferencia entre masa y minoría. Spengler denuncia el desasosiego que en el cuerpo social ocasiona su creciente contraste, que implica envidia y desprecio entre los tipos humanos. En Ortega apreciamos más bien una «rebelión» entendida como insumisión, desapego, alejamiento de la masa respecto a la minoría, a su vez culpable de una deserción histórica.

Esta es la forma fundamental de la vida humana. La «diferencia de rango existe absolutamente; y en las épocas y en los pueblos sanos es reconocida por todo el mundo como un hecho, aun cuando en los siglos de decadencia la mayoría se esfuerce por negarla o no verla». Spengler denomina a la fase tardía de una cultura «civilización», que guarda similitud con el contexto de la rebelión de las masas, en su versión orteguiana, cuya noción de «crisis de los deseos» parece vecina de la época de vejez y decadencia de la cultura tal como

20 Cf. La decadencia de Occidente, Vol. I, cap. II. 
la ve Spengler. La pérdida de los valores trae consigo el nihilismo; la filosofía y la ciencia han alcanzado el estado de decrepitud, clausurando el periodo de la metafísica, y hasta en las matemáticas no se trata ya más que de redondear y afinar. Spengler afirma que siendo la esencia de toda cultura la religión, la esencia de toda civilización es la irreligión. Ortega no repara tanto en la religión como en el nihilismo. También observa la fe en el progreso en la técnica y en su papel de sucedáneos $\mathrm{y}$, como el autor alemán, subraya el papel de la prensa.

Para Ortega una sociedad es una masa regida por una minoría. El eclipse de la minoría y el declive de su función rectora son una manifestación de la debilidad esencial de una «civilización moderna» (Cf. II, 719 y 745-6), en la que prevalecen los derechos sobre las obligaciones y que consiste en medios y no en actitudes últimas, dejando inculto el fondo de la existencia (II, 720), aquello que en la vida del hombre es lo absoluto o a través de lo cual ésta arraiga en lo absoluto. Es ésta nuestra civilización, que fomenta la indiferencia y la incapacidad del compromiso, en la que no cabe la excelencia.

Sin duda la incertidumbre y desazón que provocan la autonomía del desarrollo tecnológico y su resistencia a subordinarse a consideraciones no técnicas, así como la irresponsable fe que la masa deposita en ella, se encuentran presentes en ambos. Pero, nuevamente, el contraste: el alemán, tras la extensión de las conquistas técnicas percibe una amenaza ante la que el hombre es impotente. «Esta técnica maquinista acaba con el hombre fáustico y llegará un día en que se derrumbe y se olvidarán los ferrocarriles y los barcos de vapor, como antaño las vías romanas [...]. La historia de esa técnica se aproxima rápidamente a su término inevitable. Está carcomida por dentro, como todas las grandes formas de cualquier cultura [...]. En vista de este destino, sólo hay una concepción del universo que sea digna de nosotros [...]. El peligro se ha hecho tan grande para cada individuo, cada clase, cada pueblo, que es deplorable el pretender engañarse. El tiempo no puede detenerse; no hay prudentes retornos, no hay cautelosas renuncias. Sólo los soñadores creen en posibles salidas. El optimismo es cobardía». ${ }^{21}$ Frente a esta desconsolada concepción, la de Ortega nos parece no sólo más halagüeña, sino también más realista: si es verdad que no hay hombre sin técnica, es porque no hay hombre sin polémica, sin deseo y sin invención. Por lo mismo, también sería inhumano, un hombre sometido a la técnica. En otros términos, si es cierto que no hay hombre sin técnica, no lo es menos que no hay hombre sin capacidad de enfrentarse a la técnica.

21 El hombre y la técnica. Ed. Cit., p. 68. Queda el amor fati del soldado romano, muerto en plena erupción del Vesubio sin abandonar su puesto. «Eso es grandeza; eso es tener raza. Ese honroso final es lo único que no se le puede quitar al hombre» (69). 
En Sobre la razón histórica Ortega recuerda ${ }^{22}$ que existe en todo lo que es humano la posibilidad del naufragio y que el hombre es un animal eternamente infeliz. Pero precisamente por ello a este ser inadaptable se le presenta la vida como como stadium, esfuerzo natatorio, heroicidad; ello le impone recordar la concepción deportiva de la existencia. La vida es esfuerzo, muchas veces lujoso y gratuito. Hagamos, pues, con ella como el arquero del que habla Aristóteles. Tensando con todas nuestras fuerzas dirigiéndola a lo más alto, démosle el mayor, el mejor de los impulsos. «Si sigo en la vida es que acepto libérrimamente su penosa tarea, su angustiosa tarea. Y ese aceptar libérrimamente un penoso esfuerzo, es la definición misma del esfuerzo deportivo».

José María ATENCIA es profesor de filosofía en la Universidad de Málaga.

Lineas de Investigación:

Filosofía de la naturaleza, filosofía de la historia, filosofía española.

Publicaciones recientes:

(2013) «Aspectos del simbolismo animal en la Antigüedad clásica», en A. Diéguez y J.M. Atencia (eds.), Naturaleza animal y humana, Madrid: Biblioteca Nueva.

(2007) (ed.) Julián Marias: Una filosofía en libertad, Málaga: Universidad de Málaga, ISBN9788497472289421

Correo electrónico: jmatencia@uma.es

$22 S R H$, XII, pp. 218-219. Cf Patrick Dust, «Ortega y el papel de la cultura en la crisis de la tecnología contemporánea», Revista de Occidente, Mayo de 1989, nº 96. 
